\title{
An evaluation of the practice of active management of third stage of labour in a teaching hospital
}

\author{
Naima Fathima*, M.V. Ramana Rao
}

Department of Obstetrics and Gynaecology, SVS Medical College Hospital, Mahabubnagar, Telangana, India

Received: 26 April 2016

Accepted: 05 May 2016

\section{*Correspondence:}

Dr. Naima Fathima,

E-mail: naimaatmbnr@yahoo.com

Copyright: $(\odot$ the author(s), publisher and licensee Medip Academy. This is an open-access article distributed under the terms of the Creative Commons Attribution Non-Commercial License, which permits unrestricted non-commercial use, distribution, and reproduction in any medium, provided the original work is properly cited.

\begin{abstract}
Background: Worldwide post-partum haemorrhage (PPH) is the most common cause of maternal mortality. Atonic PPH accounts for $80 \%$ of the cases. Risk of PPH can be reduced by $60 \%$ by actively managing the third stage of labour. International Federation of Gynecology and Obstetrics (FIGO), International Confederation of Midwives (ICM) and World Health Organization (WHO) recommend routine use of active management of third stage of labour (AMTSL). The present study was done to evaluate the practices of AMTSL.

Methods: 100 Case sheets of women who had vaginal delivery were randomly taken and analyzed for the data regarding the components of AMTSL. Microsoft excel was used for analysis.

Results: The main component of AMTSL, Oxytocin 10 IU IM was used in $80 \%$ of the cases for prevention of PPH. Methylergometrine was used in $20 \%$ of the cases. Documentation of controlled cord traction was not present. Uterine massage was not routinely done and documented.

Conclusions: WHO recommends all the components of AMTSL and uterotonic is the most significant component. Controlled cord traction should be used where trained person is available. It is necessary to train the staff and create awareness about the AMTSL. Correct documentation is essential for feedback and auditing. Methylergometrine should be used as a second line drug for the treatment of post-partum haemorrhage.
\end{abstract}

Keywords: Atonic PPH, AMTSL, Maternal mortality, Oxytocin

\section{INTRODUCTION}

Post-partum haemorrhage (PPH) is the most common cause of maternal mortality and accounts for $25 \%$ of all maternal deaths worldwide. ${ }^{1}$ The most common cause of PPH is atonic PPH and majority of these deaths are preventable by adopting simple, effective, safe strategies such as active management of third stage of labour (AMTSL). Active management is superior to expectant management in reducing the blood loss. Routine use of AMTSL for all vaginal singleton births in health facilities is recommended by the International Federation of Gynecology and Obstetrics (FIGO), International Confederation of Midwives (ICM) and World Health organization (WHO). The components of AMTSL according to FIGO-ICM includes use of a uterotonic immediately following delivery of the foetus, controlled cord traction and fundal massage immediately after delivery of the placenta. ${ }^{2,3}$ Revised guidelines by WHO in 2012 recommend palpation of the uterus every 15 minutes for 2 hours to assess the tone. ${ }^{4}$

\section{METHODS}

This study was done at a district level tertiary care hospital. A data collection form was prepared. 100 case sheets of women who had vaginal delivery were randomly taken and data was entered into the form and excel. Case sheets were analyzed for documentation of all the components of AMTSL according to FIGO was 
performed or not. If any of the components were not documented, it was considered as not done.

\section{RESULTS}

There were $52 \%$ of unbooked and $48 \%$ booked cases. Primi were $18 \%$, para 1 were $36 \%$, para 2 were $32 \%$, para 3 and more were $14 \%$. Risk factors for $\mathrm{PPH}$ were, multiparity $46 \%$, anaemia of moderate to severe grade was present in $25 \%$, pre-eclampsia $10 \%$, twins $2 \%$, hydramnios $1 \%$ of cases (Table 1 ).

Table 1: General characteristics.

\begin{tabular}{|lll|}
\hline Variable & & Percentage \\
\hline \multirow{5}{*}{ Booking status } & Unbooked & 52 \\
\cline { 2 - 3 } & Booked & 48 \\
\hline & Primi & 18 \\
\cline { 2 - 3 } & Para 1 & 36 \\
\cline { 2 - 3 } & Para 2 & 32 \\
\cline { 2 - 3 } Risk factors & Para 3 & 14 \\
\hline & Multiparity & 46 \\
\cline { 2 - 3 } & Anaemia & 25 \\
\cline { 2 - 3 } & Preeclampsia & 10 \\
\cline { 2 - 3 } & Twins & 2 \\
\cline { 2 - 3 } & Hydramnios & 1 \\
\hline
\end{tabular}

Oxytocin 10 IU IM was given in $80 \%$ of cases. But this was documented in the doctors' notes in $50 \%$ of the cases only. The nurses' notes were also checked. The timing of uterotonic administration was not documented. IV infusion of oxytocin was given in $100 \%$ of cases. The dose varied 10-20 IU. In $20 \%$ of cases methyl ergometrine was used. Placental delivery by controlled cord traction was not documented. There was no documentation on fundal massage after delivery (Table 2).

Table 2: Components of AMTSL.

\begin{tabular}{|c|c|c|c|}
\hline \multicolumn{3}{|c|}{ AMTSL components } & Percentage $(\%)$ \\
\hline \multirow{4}{*}{ Uterotonic } & \multirow{3}{*}{ Oxytocin } & IM bolus & 80 \\
\hline & & IV bolus & None \\
\hline & & $\begin{array}{l}\text { IV } \\
\text { infusion }\end{array}$ & 100 \\
\hline & \multicolumn{2}{|c|}{ Methylergometrine } & 20 \\
\hline \multicolumn{3}{|c|}{ Controlled cord traction } & Not documented \\
\hline \multicolumn{3}{|c|}{ Fundal massage } & Not documented \\
\hline
\end{tabular}

\section{DISCUSSION}

Globally haemorrhage contributed to $27 \%$ of maternal deaths between 2003-2009. ${ }^{5}$ Post-partum haemorrhage is the most common cause of death of women during childbirth in India with $38 \%$ of maternal deaths being attributed to $\mathrm{PPH}^{6}{ }^{6}$ It is estimated that primary $\mathrm{PPH}$ occurs immediately in $70 \%$ of cases and is due to uterine atony. The blood vessels pass through the myometrial muscle cells and after delivery these muscle fibers contract effectively causing occlusion of the blood vessels. This is the primary mechanism of hemostasis after delivery. So atony of the uterus can cause massive PPH and death in spite of normal coagulation system. Two third of PPH cases occur in women with no identifiable risk factors.

Two trials (Bristol and Hinchingbrooke) have demonstrated that active management of third stage of labour is superior to expectant management and prevents upto $60 \%$ of $\mathrm{PPH}^{7-9}$ Active management when compared with expectant management, decreases incidence of $\mathrm{PPH}$, length of third stage of labour, percentage of prolonged third stage of labour >30 minutes, need for blood transfusion and need for uterotonic drugs to manage PPH.

FIGO, ICM and WHO recommend AMTSL. In 2006, WHO recommended all the components of AMTSL. In a hospital setting it is possible to implement all the components of active management of third stage. But in places where skilled birth attendant or a trained person is not available, it is not possible to practice all the components of third stage of labour such as controlled cord traction.

One study has independently analyzed the effectiveness of the different components of the AMTSL. This study revealed that controlled cord traction reduced the risk of $\mathrm{PPH}$ by $50 \%$ where oxytocin was not given. Combined intramuscular oxytocin and controlled cord traction reduced PPH risk by $66 \%$. Where only oxytocin was used, IV route was most effective in reducing the risk of $\mathrm{PPH}$ by $76 \%$ when compared with IM oxytocin. ${ }^{10}$

So in 2011, WHO conducted a multicenter, randomized controlled trial to compare simplified package (uterotonic without controlled cord traction) and full package (uterotonic with controlled cord traction. ${ }^{11}$ This trial has shown that oxytocin $10 \mathrm{IU}$ IM/IV without controlled cord traction (CCT) is not inferior than the full AMTSL package with regard to reducing blood loss $\geq 1000 \mathrm{~mL}$ in the third stage of labour. It was noted that CCT has minimal added value in terms of reducing blood loss over and above the uterotonic. ${ }^{16}$ Based on the findings of this trial, WHO revised the guidelines and recommends uterotonic universally and CCT as an optional component to be practiced where skilled birth attendant/trained person is available for delivery. Misoprostol $600 \mu \mathrm{g}$ orally is recommended in the absence of oxytocin.

Though FIGO recommends routine use of AMTSL, its practice is not uniform in hospitals. There is wide variation in practicing the different components of AMTSL. In one Egyptian hospital, third stage management practices were observed and it was found that third stage active management was correctly done in $15 \%$ of women observed. ${ }^{12}$ In one WHO's facility based study of AMTSL in six countries where labour practices were directly observed in the third stage, it was reported 
that $94 \%$ of the women observed were given oxytocin or another uterotonic. There was variation between the countries in the practices CCT, uterine massage and timing of uterotonic administration. It was also found that only $36 \%$ of the providers had received training in previous 3 years. ${ }^{13}$

A study done in 2005-2006 in seven countries reported that AMTSL was correctly implemented in only $0.5-32 \%$ of deliveries observed. ${ }^{14}$

In India a study was done in public health facilities in 4 districts where deliveries were observed for uterotonic drug usage practices. Uterotonic usage following delivery ranged from 78.6-99.1\% across four districts. AMTSL according to Indian guidelines in the four districts was less than $10 \%{ }^{15}$

It is encouraging that uterotonic was used in almost all cases. However oxytocin was used in $80 \%$ of the cases only. Methyl ergometrine is associated with adverse effects such as nausea, vomiting, diarrhoea, coronary artery vasoconstriction and severe systemic hypertension. Hence it is no longer recommended to use for prevention of PPH and it should be used only as a second line drug for treatment of PPH. IV infusion of 20-40IU of oxytocin in 500 or $1000 \mathrm{~mL}$ of $\mathrm{NS}$ at $150 \mathrm{~mL} / \mathrm{hr}$ is considered an acceptable alternative regimen which will help the uterus to remain retracted. The infusion was given in $100 \%$ of cases. The weakness of this study is that the practices were not observed directly. The timing of uterotonic administration was not documented. Even though placental delivery is commonly done by controlled cord traction, it was not documented. The documentation has to be improved and the components of AMTSL should be documented appropriately for review and audit purposes. The staff needs to be given feedback about accuracy and importance of documentation.

National health mission, Ministry of health and family welfare, government of India has issued guidelines in 2015 on prevention and treatment of PPH. The guideline strongly recommends the use of oxytocin along with 2 other steps, i.e CCT and uterine massage. A significant number of women still deliver in India in remote and peripheral areas where a skilled birth attendant usually is not available. To prevent PPH in those women who deliver at home, government of India prepared reference manual for advance distribution of misoprostol in the community by ASHA/ANM workers to distribute to women as misoprostol as it is effective, heat stable, feasible and safe. Misoprotol has been shown to be very effective in the prevention of $\mathrm{PPH}$.

\section{CONCLUSION}

Dissemination of knowledge, training of providers, guidelines, and auditing would ensure widespread implementation of AMTSL and reduction in maternal mortality due to PPH. In low resource settings strategies should be directed to implement routine use of simplified package (uterotonic without CCT) which has been proven very effective.

Funding: No funding sources

Conflict of interest: None declared

Ethical approval: Not required

\section{REFERENCES}

1. Trends in maternal mortality: 1990 to 2015. Estimates by WHO, UNICEF, UNFPA, World Bank Group and the United Nations Population Division.

2. International confederation of midwives, International Federation of Gynecology and Obstetrics. Joint statement: Management of the third stage of labour to prevent post-partum haemorrhage. London: FIGO; 2003.

3. International Confederation of Midwives, International Federation of Gynecology and Obstetrics. Prevention and treatment of post-partum haemorrhage: new advances for low resource settings. Int J Gynecol Obstet. 2007;97(2):160-3.

4. WHO recommendations for the prevention and treatment of postpartum haemorrhage. Geneva: World Health Organization; 2012. Available at http://apps.who.int/iris/bitstream/10665/75411/1/97 89241548502_eng.pdf. Accessed 25 February 2015.

5. Lale S, Doris C, Alison G, Ozge T, Ann BM, Jane D, et al, Global causes of maternal death: a WHO systematic analysis. Lancet Global Health. 2014; 2(6):323-333.

6. Guidance note on prevention and management of post-partum haemorrhage. Available at http:// nrhm.gov.in/nrhm-components/rmnch-a/ maternalhealth/guidelines.html. Accessed on 25 February 2015.

7. Prendiville WJ, Harding JE, Elbourne DR, Stirrat GM. The bristol third stage trial: active versus physiological management of third stage of labour. British Med J. 1988;297(6659):1295-300.

8. Rogers J, Wood J, Mc R, Ayers S, Truesdale A, Elbourne D. Active versus expectant management of third stage of labour: the Hinchingbrooke randomised controlled trial. Lancet. 1998;351(9104):693-9.

9. Begley CM, Gyte GM, Devane D, Mc W, Weeks A. Active versus expectant management for women in the third stage of labour. Cochrane Database Syst Rev. 2015;9(11):CD007412.

10. Sheldon WR, Durocher J, Winikoff B, Blum J, Trussell J. How effective are the components of active management of the third stage of labor? BMC Pregnancy Childbirth. 2013;13:46.

11. Gulmezoglu AM, Lumbiganon P, Landoulsi S, Widmer M, Abdel AH, Festin M, et al. Active management of the third stage of labour with and without controlled cord traction: a randomised, controlled, non-inferiority trial. Lancet. 2012:379(9827);1721-7. 
12. Cherine M, Khalil K, Hassanein N, Sholkamy H, Breebaart M, Elnoury A. Management of the third stage of labor in an Egyptian teaching hospital. Int J Gynaecol Obstet. 2004;87(1):54-8.

13. Bartlett L, Cantor D, Lynam P, Kaur G, Rawlins B, Ricca $\mathrm{J}$ et al. Facility-based active management of the third stage of labour: assessment of quality in six countries in sub-Saharan Africa. Bull World Health Organ. 2015;93(11):759-67.

14. Stanton C, Armbruster D, Knight R, Ariawan I, Gbangbade S, Getachew A et al. Use of active management of the third stage of labour in seven developing countries. Bull World Health Organ. 2009;87(3):207-15.

15. Stanton CK, Deepak NN, Mallapur AA, Katageri GM, Mullany LC, Koski A, et al. Direct observation of uterotonic drug use at public health facility-based deliveries in four districts in India. Int J Gynaecol Obstet. 2014;127(1):25-30.

16. Rath W. Active management of the third stage of labour (AMTSL) the end of a 50 years-dogma? Z Geburtshilfe Neonatol. 2013;217(5):173-6

Cite this article as: Fathima N, Ramana RMV. An evaluation of the practice of active management of third stage of labour in a teaching hospital. Int $\mathbf{J}$ Reprod Contracept Obstet Gynecol 2016;5:1705-8. 